\title{
Reduced Exercise Capacity in Non-Cystic Fibrosis Bronchiectasis
}

\author{
Soumya Swaminathan, K.V. Kuppurao, N. Somu ${ }^{1}$ and V.K. Vijayan ${ }^{2}$ \\ Tuberculosis Research Centre, Mayor VR Ramanathan Road, Chetput, Chennai, \\ IInstitute of Child Health and Hospital for Children, Egmore, Chennai, \\ ${ }^{2}$ Vallabhbhai Patel Chest Institute, University of Delhi, Delhi, India.
}

\begin{abstract}
Objective : Bronchiectasis not due to cystic fibrosis is usually a consequence of severe bacterial or tuberculous infection of the lungs, which is commonly seen in children in developing countries. Our aim was to study its functional sequelae and affect on work capacity in children. Methods : Seventeen children (7-17years of age) with clinical and radiological evidence of bronchiectasis of one or both lungs were studied at the Cardiopulmonaly Unit of the Tuberculosis Research Centre. Pulmonary function tests including spirometry and lung volume measurements were performed. Incremental exercise stress test was done on a treadmill, and ventilatory and cardiac parameters we monitored. Control values were taken from a previous study. Results : Children with bronchiectasis had lower forced vital capacity (FVC) $(1.1+0.4 \mathrm{~L}$ versus $1.5+0.4 \mathrm{~L}, \mathrm{p}=0.003)$ and $\mathrm{FEV}_{1}(0.95 \pm 0.2 \mathrm{~L}$ versus $1.4 \pm 0.3 \mathrm{~L}, \mathrm{p}<0.002)$ compared to age- and sex-matched healthy controls. The patient group had significantly higher residual lung volumes $(0.7 \pm 0.3 \mathrm{~L}$ versus $0.4+0.1 \mathrm{~L}, \mathrm{p}<0.02)$. At maximal exercise, they had lower aerobic capacity $(28 \pm 6 \mathrm{ml} / \mathrm{min} / \mathrm{kg}$ versus $38 \pm 5 \mathrm{ml} / \mathrm{min} / \mathrm{kg}, \mathrm{p}<0.0001)$ and maximal ventilation $(24 \pm 8 \mathrm{~L} / \mathrm{min}$ versus $39 \pm 10$ $\mathrm{L} / \mathrm{min}, \mathrm{p}<0.001)$. At maximal exercise, while none of the controls desaturated, oxygen saturation fell below $88 \%$ in eight of 17 patients. conclusion ; The findings show that children and adolescents with non-cystic fibrosis bronchiectasis have abnormal pulmonary function and reduced exercise capacity. This is likely to interfere with their lie as well as future work capacity. Efforts should be made to minimize lung damage in childhood by ensuring early diagnosis and instituting appropriate treatment of respiratory infections. [Indian J Pediatr 2003; 70 (7) : 553-556] E-mail : doctorsoumya@yahoo.com
\end{abstract}

\section{Key words : Bronchiectasis; Exercise limitation; Aerobic capacity; Children; Pulmonary function}

The prevalence of non-cystic fibrosis $(\mathrm{CF})$ bronchiectasis in developed countries has decreased over the past three decades. ${ }^{1}$ This change is largely due to greater availability of antibiotics for treatment of respiratory tract infections, a decrease in the incidence of tuberculosis and the widespread use of immunization in childhood. However, non-CF bronchiectasis, caused due to severe bacterial or tuberculous infection of the lungs, remains an important cause of morbidity and mortality among children in developing countries. ${ }^{2}$ To the best of our knowledge, its functional sequelae and influence on work capacity among children have not been studied.

Loss of lung function due to disease can be measured by resting pulmonary function and maximal work capacity. Exercise stress tests are done to evaluate the physical fitness and cardiopulmonary status of children.3,45 The aerobic capacity or maximal work capacity is an index of overall physical fitness and the other parameters measured during exercise help to differentiate between cardiac and pulmonary causes of exercise intolerance. In addition, exercise testing can be used to monitor patients with chronic lung diseases and

Reprint requests : Dr. Soumya Swaminathan, Tuberculosis Research Centre, Mayor VR Ramanathan Road, Chetput, Chennai-600031, India. Fax : 91-44-8228894. in predicting clinical course or outcome. Though exercise testing has been used to evaluate work capacity in children with cystic fibrosis, this has not been studied for children with non-CF bronchiectasis. ${ }^{6,7}$

The present study was aimed to measure the cardiorespiratory response to exercise in children and adolescents with bronchiectasis, to assess the nature and severity of the functional abnormality and correlate it with resting lung function measurements.

\section{MATERIALS AND METHODS}

The study was conducted between January 1993 and February 1994. All children attending the Pulmonology clinic of the Institute of Child Health, Egmore, Chennai were assessed clinically and radiologically. Children who had radiological features of bronchiectasis (cystic changes in one or more lung zones with or without atelectasis) and whose parents provided consent for pulmonary function testing were included in the study. The diagnosis of bronchiectasis was based on clinical and radiological (Xray) features. Pulmonary function tests on each child were conducted when they did not have acute respiratory symptoms. 


\section{Soumya Swaminathan et al}

\section{BASELINE CHARACTERISTICS}

Seventeen children (9 girls and 8 boys) with bronchiectasis, in the age group 7 to 17 years, were studied. Four of them had bronchiectasis localized to one lobe, while the others had disease involving two or more lobes of the lung. The children had suffered from the condition for varying periods of time from 1 to 5 years. Baseline characteristics of the study particiapants are given in Table 1. Body mass index (BMI) was lower than predicted, indicating moderate malnutrition. The mean haemoglobin of the study group was within normal limits but three patients were moderately anaemic. Serum total protein, albumin and globulin also were within normal limits. Erythrocyte sedimentation rate (ESR) was elevated in most of the patients.

Table1. Baseline Characteristics of 17 Patients with Bronchietasis

\begin{tabular}{lccc}
\hline & Mean & SD & Range \\
\hline Age (Years) & 10 & 2.7 & $7-17$ \\
Height $(\mathrm{cm})$ & 125 & 11.8 & $107-151$ \\
weight $(\mathrm{kg})$ & 21.5 & 5.5 & $16.5-38.3$ \\
Body mass index (g/dl) & 0.14 & 0.02 & $0.11-0.18$ \\
Haemoglobin $(\mathrm{g} / \mathrm{dl})$ & 11.7 & 1.85 & $8-15$ \\
Total protein $(\mathrm{g} / \mathrm{dl})$ & 6.7 & 0.6 & $6.0-8.8$ \\
Albumin $(\mathrm{g} / \mathrm{dl})$ & 4.1 & 0.2 & $3.7-4.6$ \\
Globulin $(\mathrm{g} / \mathrm{dl})$ & 2.6 & 0.6 & $1.7-4.3$ \\
Erythrocyte sedimentation & 31 & 23 & $4-90$ \\
rate (mm/hour) & & & \\
\hline
\end{tabular}

Pulmonary functionand exercise stress tests were then performed in the Cardiopulmonary Medicine Unit of the Tuberculosis Research Centre, Chennai. The forced vital capacity (FVC) and forced expiratory volume in 1 second $\left(\mathrm{FEV}_{1}\right)$ were measured by spirometry (Morgan Transfer Test Model C, Chatham, UK). Functional residual capacity (FRC), residual volume (RV) and total lung capacity (TLC) were measured using multiple helium dilution technique. Peak expiratory flow rate (PEFR) was measured with a Wright's peak flow meter.

An incremental exercise test (using the modified Bruce protocol) was then performed using a computerized treadmill system (Morgan, Chatham, UK). The procedure was explained in detail to the children and they were given time to get used to the treadmill and all other attachments. Throughout the test, the child breathed through a mouthpiece and wore nose clips. Expired gas was collected via a low resistance, small dead space Rudolph valve. Ventilatory parameters were measured with an intake turbine ventilometer. Expired oxygen content was determined with a Model QA 500 paramagnetic analyser and carbon dioxide content was measured by a Model 901 infrared $\mathrm{CO}_{2}$ analyser (PK Morgan Instrument Inc). Data were supplied to a Magna 88 computer, which provided 15-s averages of oxygen consumption, minute ventilation, tidal volume, respiratory rate, respiratory exchange ratio and ventilatory equivalents for oxygen and carbon dioxide. Analysers were calibrated with gases of known concentration before each testing session.

Heart rate and arterial oxygen saturation were monitored by pulse oximetry during the exercise test. Each child started exercising at a speed of $3 \mathrm{~km} / \mathrm{h}$ and zero grade. The speed and grade were increased every minute till the child could not exercise any further or there was a significant drop in $\mathrm{O}_{2}$ saturation. Peak expiratory flow rates were measured at 5, 10 and 15 minutes after exercise. The children were observed for 2 hours after the test and then sent home.

The study design was approved by the Institutional Ethical Committee and informed consent was obtained from the parents prior to the test.

\section{Controls}

The authors have previously performed exercise stress tests in healthy schoolchildren aged 7 to 14 years, of the same ethnicity, using the same equipment and testing protocol. Age- and sex- matched control values were selected from this data set. ${ }^{8}$

\section{Statistical Methods}

Data were entered and analyzed using Microsoft Excel program. The pulmonary function and exercise parameters for patients were compared with age and sexmatched control values, using Student's two-tailed t-tests. Correlation coefficients were calculated between the various parameters.

\section{RESULTS}

All the children cooperated well to complete the pulmonary function and exercise tests. Thirteen children performed a maximal exercise test reaching $85 \%$ of the predicted heart rate (HR) for their age and the others stopped before that. All the patients stopped exercise because of dyspnoea. None of the children developed complications such as wheezing or arrhythmias during or after the test.

\section{Resting Pulmonary Function}

Table 2 shows the resting pulmonary function test results for the patients. Predicted values for each child were calculated from available reference values.9,10,11 Forced vital capacity (FVC) and forced expiratory volume in 1 second $\left(\mathrm{FEV}_{1}\right)$ were decreased significantly compared to predicted values. Functional residual capacity (FRC) and total lung capacity (TLC) were within the normal range. Residual volume (RV) and RV/TLC ratio were increased significantly, indicating that hyperinflation and air trapping were mostly responsible for the reduction in vital capacity.

\section{Maximal Exercise}

At maximal exercise, maximal oxygen consumption $\left(\mathrm{VO}_{2}\right.$ 
Table 2. Resting Pulmonary Function in Patients with Bronchiectasis

\begin{tabular}{|c|c|c|c|c|}
\hline & $\begin{array}{c}\text { Bronchiectasis } \\
\text { group } \\
\text { Mean (SD) }\end{array}$ & Range & $\begin{array}{l}\text { predicted } \\
\text { value. } \\
\text { Mean(SD) }\end{array}$ & $\mathrm{p}$ value \\
\hline FVC (L) & $1.12(0.40)$ & $0.4-2.1$ & $1.54(0.37)$ & 0.003 \\
\hline $\mathrm{FEV}_{1}(\mathrm{~L})$ & $0.95(0.2)$ & $0.3-1.3^{-}$ & $1.39(0.34)$ & 0.0002 \\
\hline $\mathrm{FEV}_{1} \%$ & $80.2(9.7)$ & $57-93$ & $>80 \%$ & NS \\
\hline FRC (He) (L) & $1.08(0.3)$ & $0.8-1.8$ & $1.0(0.29)$ & NS \\
\hline TLC (L) & $1.84(0.45)$ & $1.5-3.1$ & $1.9(0.6)$ & 0.05 \\
\hline RV (L) & $0.71(0.33)$ & $0.25-1.1$ & $0.4(0.12)$ & 0.02 \\
\hline RV/TLC & 38.7 (17) & $14-68$ & $<28 \%$ & - \\
\hline
\end{tabular}

*Predicted values for each child were taken from reference values $10,11,12$

NS : not significant

$\max )$, heart rate $(\mathrm{HR})$ and maximal ventilation $\left(\mathrm{V}_{\mathrm{E}} \max \right)$ were significantly reduced compared to that in controls (Table 3). Arterial oxygen desaturation (below 88\%) during exercise was seen in eight patients but was not observed in any of the controls. However, respiratory rate (fR) and ventilatory equivalent for oxygen $\left(\mathrm{V}_{\mathrm{E}} / \mathrm{VO}_{2}\right)$ were within normal limits.

\section{(a) Maximal Oxygen Uptake}

Maximal oxygen uptake at peak exercise ranged from 17 to $38 \mathrm{ml} / \mathrm{min} / \mathrm{kg}$ (mean $28.1 \pm 5.8 \mathrm{ml} / \mathrm{min} / \mathrm{kg}$ ). This was significantly lower than that of the control group $(37.8 \pm 4.8$ $\mathrm{ml} / \mathrm{min} / \mathrm{kg}, \mathrm{p}<0.001)$. $\mathrm{VO}_{2} \max$ correlated significantly withVEmax $(\mathrm{r}=0.75, \mathrm{p}<0.01), \mathrm{FVC}(\mathrm{r}=0.465, \mathrm{p}<0.05)$, and negatively withRV/TLC ratio $(\mathrm{r}=0.538, \mathrm{p}<0.05)$. Among the six children who had normalFVC $(>80 \%$ predicted $)$ at rest, four had $\mathrm{VO}_{2} \max <75 \%$ predicted.

\section{(b) Mimimum Ventilation}

$\mathrm{V}_{\mathrm{E}}$ max ranged from 9.6 to $37 \mathrm{~L} / \mathrm{min}$ with a mean of $24.0 \pm 7.8 \mathrm{~L} / \mathrm{min}$, which was significantly lower than that in the controls $(39 \pm 9.8 \mathrm{~L} / \mathrm{min})$. The lower ventilation achieved was mainly due to a failure of the tidal volume to increase, as the respiratory rate achieved was close to the predicted value. The $\mathrm{V}_{\mathrm{E}}$ max correlated positively with FVC $(r=0.721, p<0.01)$, PEFR $(r=0.652, p<0.001)$ and TLC $(\mathrm{r}=0.61, \mathrm{p}<0.01)$ and negatively with RV/TLC ratio ( $\mathrm{r}=-$ $0.48, \mathrm{p}<0.05)$.

\section{(c) Oxygen Saturation}

Oxygen saturation at peak exercise reflects the adequacy of the cardiopulmonary system. The mean saturation of patients with bronchiectasis at maximal exercise was $88+5.6 \%$, which was significantly lower than that of the controls who maintained a saturation of $92+4.5 \%, \mathrm{p}<0.01$. Eight patients desaturated to $48 \%$ during exercise, which did not happen in any of the controls.

\section{(d) Exercise Induced Bronchospasm}

Exercise-induced bronchospasm was diagnosed if the PEFR fell by $15 \%$ or more, within 15 minutes after exercise. Four of the 17 patients had evidence of exerciseinduced bronchospasm, but none of them developed wheezing or breathlessness.

\section{DISCUSSION}

Bronchiectasis occurs following chronic bronchial sepsis in which the affected part of the bronchial tree is distorted by thickening of its lumen leading to blind endings, the bronchial wall and lumen being the seat of a chronic inflammatory reaction, retained mucus and a colonizing flora of microorganisms. There is often air trapping, hyperinflation and evidence of obstructive airway disease. This in turn could lead to limitation of activity and exercise, thereby affecting the quality of life of these patients. Cystic fibrosis is the commonest cause of bronchiectasis in developed countries; however, in developing countries, post-inflammatory bronchiectasis persists, due to the high prevalence of childhood pulmonary infections. ${ }^{2}$

This study shows that patients with non-cystic fibrosis bronchiectasis have reduced exercise tolerance. In healthy subjects, exercise is limited by cardiac mechanisms, i.e the circulatory delivery of oxygen, not the lungs. Oxygen consumption generally increases till it reaches a plateau and minute ventilation and cardiac output increase linearly with work rate. The arterial oxygen and carbon dioxide levels remain relatively stable during exercise..$^{12}$ In contrast, the authors observed that the aerobic capacity (maximal oxygen consumption) and maximum ventilation achieved by patients with bronchiectasis were both significantly lower than age and sex matched ethnic controls. The inabiity to exercise maximally was mainly

TABLE 3. Cardiorespiratory Parameters st Maximal Exercise

\begin{tabular}{|c|c|c|c|c|}
\hline \multirow[t]{2}{*}{ Parameter } & \multicolumn{2}{|c|}{ Bronchiectasis group } & \multirow{2}{*}{$\begin{array}{l}\text { Healthy controls } \\
\text { Mean (SD) }\end{array}$} & \multirow[t]{2}{*}{$\mathrm{p}$ value } \\
\hline & $\operatorname{Mean}(\mathrm{SD})$ & Range & & \\
\hline $\mathrm{VO}_{2} \max (\mathrm{ml} / \mathrm{kg} / \mathrm{min})$ & $28.1(5.8)$ & $17-38$ & $37.8(4.8)$ & $<0.0001$ \\
\hline $\mathrm{HR}$ (beats/min) & $179(14.6)$ & $50-200$ & $207(8.5)$ & $<0.0001$ \\
\hline RR (breaths/min) & $63(5)$ & $50-88$ & $63(4)$ & NS \\
\hline $\operatorname{VEmax}(\mathrm{L} / \mathrm{min})$ & $24(7.8)$ & $9.6-37$ & $39(9.8)$ & $<0.001$ \\
\hline $\mathrm{VE} / \mathrm{VO}$ & $42.4(5.6)$ & $28-50$ & $40.1(5.6)$ & NS \\
\hline $\mathrm{O}_{2} \operatorname{Sat}(\%)$ & $88(5.6)$ & $77-98$ & $92(4.5)$ & $<0.01$ \\
\hline
\end{tabular}


due to a failure to increase minute ventilation, which could not meet the increased oxygen demand during exercise. Further, the maximal oxygen uptake correlated with resting FVC and negatively with the RV/TLC ratio, indicating that a reduced vital capacity and hyperinflation adversely affect exercise tolerance. Even among patients who had normal resting pulmonary function, an incremental exercise test demonstrated the limitation of work capacity, confirming that the exercise stress test is a sensitive tool to evaluate respiratory disease.

Eight patients had a significant fall in oxygen saturation during exercise, again indicating an impairment of their exercise capacity. In healthy children, the authors found no instance of oxygen saturation falling below $88 \%$ at peak exercise. The fall in saturation could be due to a mismatch in ventilation and perfusion that was aggravated during exercise. Four children developed exercise-induced bronchaspasm, indicating the presence of bronchial hyper-reactivity. This could be due to the chronic inflammation of the airways. However, none of the children developed clinical wheezing or dyspnoea.

Though studies of exercise performance in non-CF bronchiectasis are rare, cystic fibrosis, a similar condition, has been well studied. Nutritional status and exercise tolerance in $\mathrm{CF}$ patients have been shown to be associatd with prognosis and survival. ${ }^{6,7}$ Patients with CF have diminished work capacity and an increased oxygen cost of exercise. ${ }^{13}$ Muscle weakness and low fat free body mass are associated with decreased physical performance; FVC and $\mathrm{FEV}_{1}$ were also shown to correlate with Wmax and $\mathrm{VO}_{2}$ max in patients with moderate $\mathrm{CF}$ but not in children with mild $\mathrm{CF}$ or in healthy children. ${ }^{14}$ In the present study, though the BMI of patients was lower than that predicted for age, it did not contribute towards the reduction in $\mathrm{VO}_{2} \max (\mathrm{r}=0.03)$, suggesting that malnutrition was not primarily responsible for exercise limitation.

The authors have demonstrated that children with non-CF bronchiectasis have exercise limitation, which correlates with the severity of lung function abnormality. This cross-sectional study involved a relatively small number of patients. Longitudinal studies with regular monitoring of pulmonary function and exercise capacity would help in relating the results of these tests to prognosis and outcome. Further, the benefit of interventions such as oral or aerosolized antibiotics, pulmonary physiotherapy or a rehabilitation programme can be assessed more objectively. To prevent the development of bronchiectasis and thereby reduce chronic ill-health and impaired quality of life in these patients, attempts should be made to diagnose and treat respiratory infections appropriately.

\section{Acknowledgements}

The authors are grateful to the subjects who participated in this study. We would like to express our gratitude to the Director, Institute of Child Health, Egmore, Chennai and the staff of the Pulmonology Department for their cooperation in the conduct of this study. We are also grateful to Mr K. Sankaran, R.A. and Late Mrs Annamma Joy, CN for their assistance and technical support. We thank Dr R. Prabhakar, Director (Retired), Tuberculosis Research centre, for his constant encouragement and support.

\section{REFERENCES}

1. Dagli E. Non cystic fibrosis bronchiectasis. Pediatr Respir Rev 2000; 1: 64-70.

2. sethi GR, Batra V. Bronchiectasis causes and management. Indian J Pediartr 2000; 67(2) : 133-139.

3. NixonPA, OrensteinDM. Exercise testing inchildren. Pediatr Pulmonol 1988; 5 : 107-122

4. Platzker ACG, Keens TG. Pulmonary function testing in pediatric patients. In Wilson AF, ed. Pulmonary Function Testing. Indications and Interpretation. Florida, Grune and shatton, 1985; 275-292.

5. swaminathan s. Exercise testing in children: Indications and Technique. Indian JPediatr 1991; 58 : 305-330.

6. Nixon PA, Orenstein DM, Kelsey SF, Doershuk CF. The prognostic value of exercise testing in patients with cystic fibrosis. NEngJMed 1992-327: 1785-1788.

7. Corey M, McLoughlin MC, William M and Levison H. A comparison of survival, growth and pulmonary function in patients with cystic fibrosis in Boston and Toronto. J Clin Epidemiol 1988;41: 583-591

8. Swaminathan S, Vijayan VK, Venkatesan P, Kuppu Rao KV. Aerobic Capacity and cardiopulmonary response to exercise in healthy south Indian children. Indian pediatr 1997; 34 :112-118.

9. Chowgule RV, shetye VM, Parmer JR Lung function tests in normal Indian children. Indian Pediatr 1995;32:185-191.

10. Vijayan VK, Reetha AM, Kuppurao KV, Venkatesan P, Thilakavathy S. pulmoarary function in normal South Indian children aged 7 to 19 years. Indian J Chest Dis Allied Sci 2000; 42: 147-156.

11. Polgar G, promadhat V. Pulmonary Function Testing in Children Techniques and Standards. Philadelphia, WB Saunders, 1971;88 95.

12 Morgan MDL. Exercise testing. In HughesJMB,pride NB,eds Lung Function Tests: Physiological Principles and Clinical Applications. WBSaunders, UK, 2000; 134-148.

13. Gulmans VAM, de Meer K, Brackel HJL, Helders PJM. Maximal work capacity in relation to nutritional status in children with cystic fibrosis Eur Respir J 1997;10:2014-2017

14. De Meer K, Gulmans VAM, van der Laag J. Peripheral muscle weakness and exercise capacity in children with cystic fibrosis Am J Respir Crit Care Med 1999; 159 : 748-754. 